\title{
Fetal Behavior in 4D Ultrasound in the Progress of Perinatal Medicine
}

\author{
Asim Kurjak ${ }^{1}$, Maja Predojević ${ }^{2 *}$, and Aida Salihagić Kadić 3,4 \\ ${ }^{1}$ Department of Obstetrics and Gynecology, Clinical Hospital Sveti Duh, Medical School, University of Zagreb, Zagreb, Croatia \\ ${ }^{2}$ Department of Obstetrics and Gynecology, Fetomaternal Unit, Hamad Medical Corporation, Doha, Qatar \\ ${ }^{3}$ Department of Physiology, Medical School, University of Zagreb, Zagreb, Croatia \\ ${ }^{4}$ Croatian Institute for Brain Research, Medical School, University of Zagreb, Zagreb, Croatia
}

\begin{abstract}
It has been suggested that the assessment of fetal behavior and developmental processes in different periods of gestation may make possible the distinction between normal and abnormal brain development, as well as early diagnosis of various structural or functional abnormalities. Early detection and prevention of perinatal neurological damage are one the most important tasks of perinatal medicine. Development of modern imaging method, four dimensional sonography, provided us new insight into fetal behavior. The aim of this review is to present prenatal neurologic screening test for the assessment of fetal behavior, based on four dimensional ultrasound. Test is named Kurjak Antenatal Neurodevelopmental Test (KANET). Up to know assessment of fetal behavior using KANET provided very promising results.
\end{abstract}

Keywords: Fetal behavior; Four dimensional ultrasound; KANET; Neurodevelopment

\section{Introduction}

Fetal behavior could be described as any fetal action or reaction observed by ultrasonography [1]. Analysis of the dynamics of fetal behavior in comparison with morphological studies has led to the conclusion that fetal behavioral patterns are directly reflecting developmental and maturational processes of fetal Central Nervous System (CNS) [2-4]. Endogenous motor activity, according to Prechtl, will be affected in case of any brain damage [5]. Early detection and prevention of neurological damage are one the most important tasks of perinatal medicine. Further, it has been suggested that the assessment of fetal behavior and developmental processes in different periods of gestation may make possible, the distinction between normal and abnormal brain development, as well as early diagnosis of various structural or functional abnormalities [6].

The development of four dimensional (4D) ultrasound has significantly improved the assessment of the quality of fetal spontaneous movements, and enabled a better evaluation of fetal behavior in comparison with 2D ultrasound [7-10]. The Zagreb group, after summing their own experiences and those of the leading authors in the field of perinatal neurology, has proposed a new prenatal screening test for assessment of fetal motor activity [11]. The test was named according to the first author, the Kurjak Antenatal Neurodevelopmental Test (KANET). In order to make the test accessible, the standardization of the test was proposed in Osaka, Japan during the International Symposium on Fetal Neurology of International Academy of Perinatal Medicine held in October 2010 [12].

The aim of this review is to present contribution of modern ultrasound technology namely, 4D ultrasound, in the development of the KANET and published results of the assessment of fetal behavior using KANET.

Development of new scoring system for evaluation of fetal behavior based on prenatal assessment of fetal motor activity by $4 \mathrm{D}$ sonography

For a long time maternal registration of fetal movements and obstetrician auscultation of fetal heartbeats were the only methods of the follow-up of fetal well-being in utero. It has been shown that fetal activity occurs as early as the late embryonic period, which is far earlier than the mother can sense it [13]. Introduction of real-time ultrasound has been a turning point in the assessment of fetal behavior [2]. For the first time, studies of spontaneous prenatal movements and behavior in utero were performed and published. Since fetal body movements give important information about the condition of the fetus, their quantitative as well as qualitative aspects were analyzed [14,15].

Based on the first analysis of fetal movements by two dimensional (2D) ultrasonography, de Varies [14] classified movements into different patterns as follows: sideways bending, startle, general movements, hiccups, breathing-like movements, isolated arm or leg movement, twitches, clonic movements, isolated retroflexion of the head, isolated rotation of the head, isolated anteflexion of the head, jaw movements, sucking and swallowing, hand-head contact, stretching, yawning, rotation of the fetus.

For many years, the interest of obstetricians was focused on the quantity of fetal movements which was considered as an indicator of fetal well-being. Later studies have shown that count of movements is poor indicator of brain damage, mainly due to the great intra-and interindividual differences and the large overlap between normal and abnormal, which makes this method clinically useless [16]. On the contrary, changes of the elegance and fluency, as well as the variability and fluctuation of intensity and speed of General movements (GMs), were shown to be prominent in the sick preterm infants [16]. In addition, GMs are the first complex and the most frequent movement pattern during intrautejb rine life and are considered to be the first sign of a supra spinal control of the motor activity [17]. They appear at 8 to 9 weeks of gestation and remain present until the $20^{\text {th }}$ postnatal week

*Corresponding author: Maja Predojević, Department of Obstetrics and Gynecology, Fetomaternal Unit, Hamad Medical Corporation, Doha, Qatar, Tel: 003851 3712317; Fax: 0038514590207; E-mail: predojevic.maja@gmail.com

Received April 02, 2013; Accepted April 18, 2013; Published April 24, 2013

Citation: Kurjak A, Predojević M, Kadić AS (2013) Fetal Behavior in 4D Ultrasound in the Progress of Perinatal Medicine. J Health Med Informat S11: 006. doi:10.4172/2157-7420.S11-006

Copyright: (C) 2013 Kurjak A, et al. This is an open-access article distributed under the terms of the Creative Commons Attribution License, which permits unrestricted use, distribution, and reproduction in any medium, provided the original author and source are credited. 
[14]. It became evident that the qualitative changes in GMs of both the fetus and the neonate precede quantitative changes when the integrity of the nervous system is impaired [16]. 4D ultrasound significantly enhanced assessment of quality of general movements [18]. The majority of sequences of extension and flexion of the legs and arms is complex, and may be better assessed. Furthermore, 4D sonography seems to be the method of choice for detecting subtle changes such as superimposed rotations and changes in direction of the movements. The Gestalt-perception, which is term, was introduced by Prechtl as the overall impression on the quality of GMs [16]. He observed that, GMs are diagnosed as normal if the movements are complex, including neck, trunk and limb movements appearing in a variable sequence as fluent, and if their intensity wax and wane. If the GMs are monotonous, have less complexity and are repetitive in pattern, they are judged as abnormal and as being of 'poor repertoire.' Other abnormal patterns are the 'cramped-synchronized' type, when the movements are occurring en bloc and generalized muscle contraction and relaxation appear almost simultaneously, or the movements may occur in a jerky and exaggerated manner and in chaotic order [16]. Abnormal GMs, arm movements in circles, finger spreading and absence of asymmetric tonic neck response from birth untill the end of the $2^{\text {nd }}$ month post-term were described as early signs of disturbed neurodevelopment, and thus were the reasons for the inclusion of these parameters in the KANET [11].

Further, modern ultrasound technology, such as 4D sonography, enables study of the fetal activity in the surface-rendering mode, improves visualization of the fetal face, and opens the possibility of assessment of the fetal facial movements [19]. With 4D ultrasound, it is now possible to study a full range of facial expressions including smiling, crying, scowling and eyelid movements [20,21]. Simultaneous imaging of complex facial movements was not possible using real-time $2 \mathrm{D}$ ultrasound. $4 \mathrm{D}$ ultrasound integrates the advantage of the spatial imaging of the fetal face with the addition of time. This new technology therefore allows detailed imaging of the each fetal facial movement in time. The observation of facial expression may be of scientific and diagnostic value [22]. Facial movements which also reflect the development of the brain were also included in the scoring system KANET [11].

In addition, according to Amiel-Tison the identification of following three signs already present at birth offers a precious clue to fetal brain damage, when observed in a cluster: high-arched palate (due to insufficient molding forces of a hypoactive tongue), nonreducible adduction of the thumb in a clenched fist (due to absence of spontaneous motor activity) and cranial ridges over each suture or restricted to the squamous suture (due to severe or moderate impairment of hemispheric growth) [23-26]. Using 4D ultrasound last two of these three signs can be clearly diagnosed in utero and hence they are part of KANET parameters too [12].

Finaly, KANET includes assessment of: isolated head anteflexion, overlapping cranial sutures and head circumference, isolated eye blinking, facial alteration (grimace or tongue expulsion), mouth opening (yawning or mouthing), isolated hand and leg movements, hand to face movements, finger movements and thumb position, Gestalt perception of general movements [11].

After experience from first few multicentric studies, the new modified KANET test was proposed [12]. In addition, 8 instead of 10 parameters should be used with as follows:

- Facial and mouth movements are combined in one category
- Isolated hand movements and hand to face movements are combined in one category.

The KANET should be performed using $4 \mathrm{D}$ ultrasound in the $3^{\text {rd }}$ trimester from $28^{\text {th }}$ to $38^{\text {th }}$ week of gestation. The assessment should last from 15 to 20 minutes, and the fetuses should be examined when awake. If the fetus is sleeping, the assessment should be postponed for 30 minutes or for the next day between 14 and 16 hours. In cases of definitely abnormal or borderline score, the test should be repeated every two weeks till delivery. The score should be for neurologically abnormal fetuses 0 to 5, borderline score is from 6 to 13 and normal score is 14 or above [12].

\section{Results of KANET in low- and high-risk pregnancies}

KANET was first retrospectively applied in a group of 100 low-risk pregnancies [11]. After delivery, postnatal neurological assessment was performed, and all neonates assessed as normal reached a score between 14 and 20, which we assumed to be a score of optimal neurological development. Subsequently, the same scoring system was applied in the group of 120 high-risk pregnancies in which, based on postnatal neurological findings, three subgroups of newborns were found: normal, mildly or moderately abnormal, and abnormal. Normal neonates had a prenatal score between 14 and 20, mildly or moderately abnormal neonates had a prenatal score of 5-13, whereas those infants who were assigned as neurologically abnormal had a prenatal score of $0-5$. Ten fetuses who were postnatal described as mildly or moderately neurologically abnormal, achieved prenatal score of 5-13, whereas another ten fetuses postnatal assigned as neurologically abnormal had a prenatal score of 0-5. Among this group four fetuses had alobar holoprosencephaly, one had severe hypertensive hydrocephaly, one had tanatophoric dysplasia and four fetuses had multiple malformations. These preliminary results demonstrated the ability of KANET to identify abnormal behavior in severely neurologically damaged fetuses [11].

To verify the new scoring test, study has been continued in several collaborative centers (Zagreb, Istanbul, Bucharest, and Doha) [27]. The objective of this multicentric study was to apply the KANET to the fetuses in high-risk pregnancies for neurological disorders and to verify the results of the test by neonatal neurological assessment. This multicentric research included 228 fetuses from high-risk pregnancies, of whom 18 had definite abnormal KANET score. Of these 18 pregnancies, five pregnancies were terminated, and six fetuses died in utero. Of seven fetuses with abnormal KANET, postnatal neurological assessment by Amiel-Tison's method revealed three newborns out of seven fetuses to be abnormal (arthrogryposis, vermis aplasia and neonate of the mother with the previous child with cerebral palsy), while four were considered normal (ventriculomegaly, pre-eclampsia, thrombophilia, oligohydramnios). The fetuses in these three cases with abnormal KANET score and abnormal postnatal neurological status had especially reduced facial movements-the faces were like masks during repeated scans. Fetuses with vermis aplasia and arthrogryposis had normal cranial sutures but the isolated head flexion was small in range for both cases. Isolated hand movements, hand-to-face and leg movements were poor in repertoire for all three cases. The finger movements were cramped and invariable in all three cases. The Gestalt perception of general movements was also abnormal in these cases. In this study the behavior of a fetus with acranius was also longitudinally followed. It was observed that the fetus at 20 weeks of gestation had hypertonic movements with high amplitude and high speed. The movements emerged abruptly with burst-pause patterns, the variability of head movements was missing, and there were no changes in facial 
expressions. As the gestational age advanced and the motor control was shifting from lower to upper control center, the movement patterns also changed. At the gestational age of 32 weeks the fetus had no facial expressions (mask-like face) and hand movement repertoire was very poor. At 36 weeks the absence of both the facial expressions and limb movements was observed. In this fetus abnormal behavior patterns, as a result of lack of the appropriate control of the upper cortical centers on the motor activity, was clearly documented [27].

Another study confirmed that, a statistically significant difference in fetal behavioral patterns between the fetuses from low-risk and highrisk pregnancies [28]. Statistically significant difference for eight out of 10 parameters of KANET has been shown: isolated anteflexion of the head, eye blinking, facial expressions (grimacing, tongue expulsion), mouth movements (mouthing, jawing, swallowing), isolated hand movement, hand-to-face movement, fist and finger movements, and general movements. Statistically significant, moderate correlation of KANET and ATNAT tests was also confirmed. In a practical sense, it means that the neuropediatricians who examined the newborns with the ATNAT test confirmed the results of KANET [28].

New results regarding the potential of $4 \mathrm{D}$ sonography in the assessment of fetal behavior in high-risk pregnancies were recently published [29]. The group in Khartoum applied KANET to a large number of fetuses during a 1-year period. The aim of the study was to assess the behavior in a large sample of fetuses from normal and high-risk pregnancies by application of the KANET scoring test and to compare the scores obtained in low- and high-risk pregnancies. In this prospective longitudinal cohort study, the KANET was applied in 620 singleton pregnancies between weeks 26 and 38 of gestation. There were 520 pregnant women in the high-risk group and 100 pregnant women in low-risk group. By contrast with previous studies, the fetuses with congenital anomalies and multiple pregnancies were excluded from the study. The high-risk group of patients consisted of the following subgroups: threatened preterm delivery with or without Preterm Premature Rupture of Membranes (PPROM), previous child diagnosed with cerebral palsy, hypertension in pregnancy with or without pre-eclampsia, diabetes before pregnancy or gestational diabetes, intrauterine growth restriction, polyhydramnios, $\mathrm{Rh}$ isoimmunization, placental bleeding, and maternal fever $>39^{\circ} \mathrm{C}$. Fetal KANET scores from low and high-risk pregnancies were compared, and the difference was statistically significant. Statistically significant difference was found between KANET scores of the fetuses from the low-risk group compared with the following subgroups of the high-risk group: previous child diagnosed with cerebral palsy, hypertension (RR $>160 / 100$ $\mathrm{mmHg}$ ), threatened preterm delivery, maternal fever, intrauterine growth restriction (IUGR), $\mathrm{Rh}$ iso-immunization, placental bleeding. KANET scores also differed significantly comparing threatened preterm delivery with PPROM vs. threatened preterm delivery without PPROM; hypertension $>160 / 100 \mathrm{mmHg}$ vs. hypertension $<160 / 100$ $\mathrm{mmHg}$; diabetes before pregnancy vs. gestational diabetes; IUGR with decreased Resistance Index (RI) of Middle Cerebral Artery (MCA) vs. IUGR without decreased RI of MCA; and Rh isoimmunization without hydrops fetalis vs. Rh isoimmunization with hydrops fetalis. Among the fetuses with abnormal KANET score, one of the most represented were fetuses from the threatened preterm delivery group. Comparison of individual KANET parameters between the fetuses from the low and high-risk pregnancies showed statistically significant difference for overlapping cranial sutures and head circumference, isolated eye blinking, facial expressions (grimacing and tongue expulsion), mouth movements (yawning and mouthing), isolated hand movements, isolated leg movements, hand-to face movement, finger movements, and general movements. For isolated head anteflexion, the difference was not statistically significant. Until now, this has been the study with the largest number of fetuses (620) where prenatal KANET test was applied. The study demonstrated the potential of KANET to detect and discriminate normal from borderline and abnormal fetal behavior in normal and in high-risk pregnancies [29].

In a recently published case report KANET indicated normal early neurological development of the child, confirmed by two postnatal tests (Amiel-Tison's neurological assessment and assessment of General movements using Prechtl method), despite unfavorable intrauterine conditions, IUGR and fetal hypoxemia [30].

Athanasiadis and coworkers also assessed and compared fetal behavior and neurodevelopment using KANET in low and and high-risk pregnancies in prospective, comparative, cohort study which included 152 pregnant women [31]. According to the maternal background risk, the population of the study was classified in low-risk pregnancies $(\mathrm{n}=78)$ and high-risk pregnancies $(\mathrm{n}=74)$ with IUGR fetuses $(\mathrm{n}=12)$, diabetes mellitus $(n=24)$, and pre-eclampsia $(n=38)$. Results showed that the neurodevelopmental score was statistically significant higher in the low-risk group compared to the high-risk group. The diabetes subgroup score was statistically significantly higher compared to the IUGR and the pre-eclampsia subgroup. Authors of this study concluded that the neurodevelopment fetal assessment by $4 \mathrm{D}$ ultrasound appears to be a feasible method in the evaluation of high-risk pregnancies and that further studies where any association between KANET score and neurological outcome of the childhood are necessary [31].

To determine the role of $4 \mathrm{D}$ ultrasonography in prenatal assessment of fetal neurobehavior and in prediction of adverse neurological outcome 40 pregnant women between 20 and 38 weeks of gestation with high-risk for neurological abnormalities and 40 low-risk cases were included in prospective cohort study in Women Hospital in Doha [32]. Prenatal fetal neurological assessment was made using KANET, and postnatal neurological assessment was performed using AmielTison's neurological assessment at term for all live-borns. All cases with abnormal KANET proved to be abnormal postnatally. The difference in the range of KANET score was significant. A significant difference was shown for all KANET parameters except isolated leg movement and cranial sutures [32].

Interesting results were published by authors whose aim was to asses differences in fetal behavior in both normal fetuses and fetuses with cerebral ventriculomegaly (VM) [33]. In a period of eighteen months, in a longitudinal prospective cohort study, KANET was applied to assess fetal behavior in both normal pregnancies and pregnancies with cerebral VM. After assessment of 100 normal fetuses in the control group, and 140 fetuses with diagnosed VM, the following results were obtained: there were two fetuses with abnormal KANET score in the control group and 37 fetuses in the group with VM. The largest number of abnormal KANET scores was found in 22 fetuses with severe VM accompanied by other structural abnormalities. A borderline KANET score was found in four fetuses in the control group and twelve fetuses in the group with VM. Statistical analysis showed the significant difference between the two groups. There were no fetuses with abnormal KANET score in the group of isolated mild and moderate VM. On the other hand the difference between KANET scores was obvious in the fetuses with severe isolated VM and in mild, moderate and severe VM with additional congenital CNS malformations. Authors concluded that evaluation of the fetal behavior in fetuses with cerebral VM using KANET test has the potential to detect fetuses with abnormal behavior, and to add the dimension of CNS function to the morphological criteria 
of VM. Long-term postnatal neurodevelopmental follow-up should confirm the data from prenatal investigation of fetal behavior [33].

Recently results on assessment of fetal behavior by the KANET test in relation to fetal circulatory changes in umbilical and brain arteries, in different categories of at-risk pregnancies [34]. There were 596 fetuses in the high-risk group and 273 fetuses in the lowrisk group. Statistically significant differences in the distribution of normal, abnormal, and borderline KANET scores between low-risk and high-risk groups were found. Furthermore, fetuses from the high-risk group were subdivided into subgroups according to the risk factor. Subgroups were: pregnancy-induced hypertension, fetal growth restriction, gestational diabetes mellitus, threatened preterm birth, antepartal hemorrhage, maternal fever, sibling with cerebral palsy, Rh immunization, polyhydramnios. The largest proportion of abnormal KANET scores (23.9\%) was in the subgroup of fetuses whose mothers had an offspring diagnosed with cerebral palsy (23.9\%), followed by the proportion of borderline KANET scores in the subgroup of fetuses from febrile mothers (12.7\%). Fetal behavior was significantly different between the normal group and the following subgroups of fetuses: fetal growth restriction (FGR), gestational diabetes mellitus, threatened preterm birth, antepartal hemorrhage, maternal fever, sibling with cerebral palsy, and polyhydramnios [33]. This was the first study to examine the alteration in fetal behavior, measured by the KANET test in relation to fetal circulatory changes in umbilical and brain arteries, in different categories of at-risk pregnancies. Authors found significant differences in fetal behavior when circulatory changes in fetal brain were present. Circulatory changes were found as pathophysiologically expected in the group of FGR fetuses with abnormal fetal behavior under conditions of fetal hypoxia. It was suggested that in the escalation of pathophysiological events in utero-placental insufficiency alterations of fetal behavior occur prior to redistribution of fetal circulation towards the fetal brain in conditions of hypoxia [34].

\section{Conclusion}

As can be understand from this review the development of ultrasound technology, especially the 4D ultrasound has enabled an unprecedented insight into the neurological development of the fetus. With a multidisciplinary approach a prenatal neurologic screening test based on neurological 4D technology was proposed. Results of numerous studies using this test, called KANET, are very promising and stimulating. However, all researchers involved in the estimation of fetal behavior using KANET agree that further studies in a large population with long-term follow-up are required. According to Osaka consensus after 4D ultrasound assessment of fetal behavior in the fetuses from high-risk pregnancies, it is very important to continue with follow-up after delivery in infants who were borderline or abnormal as fetuses [12]. Postnatal assessment of neonates includes initial neurological assessment according to Amiel-Tison's methodology. If ATNAT is borderline or abnormal assessment of general movements should be performed. Brain ultrasonography should also be performed in the first week of life and every 2 weeks afterward till discharge. In severely affected infants with grade 3 and above intraventricular hemorrhage, and those highly suspicious of hypoxic ischemic brain damage, magnetic resonance should be done if available. Infants should be followed until the age of at least 24 months when diagnosis of disabling or nondisabling cerebral palsy can be ultimately made. Infants with cerebral palsy should be reassessed at the age of 6 years [12]. Further researches on KANET have been initiated in several centers with similar objectives: to assess practical clinical application of the test in both normal and high-risk pregnancies. KANET test could bring valuable progress in the field of perinatal medicine and enable early recognition of children at risk for adverse neourodevelopment who need early habilitation and additional care.

\section{References}

1. Nijhuis JG (1992) Fetal Behaviour: Developmental and Perinatal Aspects.(Ed), Oxford University Press, Oxford, USA.

2. de Vries JI, Fong BF (2006) Normal fetal motility: An overview. Ultrasound Obstet Gynecol 27: 701-711.

3. Rosier-van Dunné FM, van Wezel-Meijler G, Bakker MP, Odendaal HJ, de Vries JI (2010) Fetal general movements and brain sonography in a population at risk for preterm birth. Early Hum Dev 86: 107-711.

4. de Vries JI, Fong BF (2007) Changes in fetal motility as a result of congenita disorders: An overview. Ultrasound Obstet Gynecol 29: 590-599.

5. Einspieler C, Prechtl HFR, Bos AF, Ferrari F, Cioni G (2004) Prechtl's method on the qualitative assessment of general movements in preterm, term and young infants. Mac Keith Press, London, UK.

6. Prechtl HF (1990) Qualitative changes of spontaneous movements in fetus and preterm infant are a marker of neurological dysfunction. Early Hum Dev 23 151-158.

7. Hata T, Dai SY, Marumo G (2010) Ultrasound for evaluation of feta neurobehavioural development: from 2-D to 4-D ultrasound Infant Child Dev 19: 99-118.

8. Andonotopo W, Kurjak A (2006) The assessment of fetal behavior of growth restricted fetuses by 4D sonography. J Perinat Med 34: 471-478.

9. Kurjak A, Mišković B, Andonotopo W, Stanojević M, Azumendi G, et al. (2007) How useful is $3 D$ and $4 D$ ultrasound in perinatal medicine? J Perinat Med 35 10-27.

10. Kurjak A, Predojević M, Stanojević M, Aida Salihagic-Kadic, Berivoj Miskovic et al. (2010) Intrauterine growth restriction and cerebral palsy. Acta Med Inform 18: $64-82$

11. Kurjak A, Miskovic B, Stanojevic M, Amiel-Tison C, Ahmed B, et al.(2008) New scoring system for fetal neurobehavior assessed by three- and fourdimensional sonography. J Perinat Med 36: 73-81.

12. Stanojević M, Talić A, Miškoović B, Vasilj O, Shaddad AN, et al. (2011) An Attempt to Standardize Kurjak's Antenata INeurodevelopmental Test: Osaka Consensus Statement 5: 317-329.

13. Lüchinger AB, Hadders-Algra M, van Kan CM, de Vries Jl (2008) Fetal onset of general movements. Pediatr Res 63: 191-195.

14. de Vries JIP, Visser GH, Prechtl HF (1982) The emergence of fetal behaviour. I. Qualitative aspects. Early Hum Dev 7: 301-322.

15. de Vries JIP, Visser GHA, Prechtl HFR (1985) The emergence of fetal behaviour II. Quantitative aspects.. Early Hum Dev 12: 99-120.

16. Prechtl H (1991) Continuity of Neural Functions from Prenatal to Postnatal Life. Cambridge University Press.

17. Hadders-Algra M (2000) The neuronal group selection theory: a framework to explain variation in normal motor development. Dev Med Child Neurol 42: 566572.

18. Andonotopo W, Stanojevic M, Kurjak A, Azumendi G, Carrera JM (2004) Assessment of fetal behavior and general movements by four-dimensional sonography. Ultrasound Rev Obstet Gynecol 4: 103-114.

19. Lee A (2001) Four-dimensional ultrasound in prenatal diagnosis: Leading edge in imaging technology. Ultrasound Rev Obstet Gynecol 1: 194-198.

20. Kozuma S, Baba K, Okai T, Taketani Y (1999) Dynamic observation of the fetal face by three-dimensional ultrasound. Ultrasound Obstet Gynecol 13: 283-284.

21. Campbell S (2002) 4D or not 4D: That is the question. Ultrasound Obstet Gynecol 19: 1-4.

22. Kurjak A, Azumendi G, Andonotopo W, Salihagic-Kadic A (2007) Three- and four-dimensional ultrasonography for the structural and functional evaluation of the fetal face. Am J Obstet Gynecol 196: 16-28.

23. Amiel-Tison C, Gosselin J, Kurjak A (2006) Neurosonography in the second hal of fetal life: A neonatologist's point of view. J Perinat Med 34: 437-446. 
Citation: Kurjak A, Predojević M, Kadić AS (2013) Fetal Behavior in 4D Ultrasound in the Progress of Perinatal Medicine. J Health Med Informat S11: 006. doi:10.4172/2157-7420.S11-006

Page 5 of 5

24. Amiel-Tison C, Gosselin J, Gahagan S (2005) Why is the neurological examination so badly neglected in early childhood? Pediatrics 116: 1047-1048.

25. Gosselin J, Gahagan S, Amiel-Tison C (2005) The Amiel-Tison neurological assessment at term: Conceptual and methodological continuity in the course of follow-up. Ment Retard Dev Disabil Res Rev 11: 34-51.

26. Simard MN, Lambert J, Lachance C, Audibert F, Gosselin J (2009) Interexaminer reliability of Amiel-Tison neurological assessments. Pediatr Neurol 41: 347-352.

27. Kurjak A, Abo-Yaqoub S, Stanojevic M, Yigiter AB, Vasilj O, et al. (2010) The potential of $4 \mathrm{D}$ sonography in the assessment of fetal neurobehavior-multicentric study in high-risk pregnancies.. J Perinat Med 38: 77-82.

28. Mišković B, Vasilj O, Stanojević M, Ivanković D, Kerner M, et al. (2010) The comparison of fetal behavior in high risk and normal pregnancies assessed by four dimensional ultrasound. J Matern Fetal Neonatal Med 23: 1461-1467.

29. Talić A, Kurjak A, Ahmed B, Stanojevic M, Predojevic M, et al. (2011) The potential of $4 D$ sonography in the assessment of fetal behavior in high-risk pregnancies. J Matern Fetal Neonatal Med 24: 948-954.
30. Predojević M, Stanojević M, Vasilj O, Kadić AS (2011) Prenatal and postnatal neurological evaluation of a fetus and newborn from pregnancy complicated with IUGR and fetal hypoxemia. J Matern Fetal Neonatal Med 24: 764-767.

31. Athanasiadis AP, Mikos T, Tambakoudis GP, Theodoridis TD, Papastergiou M, et al. (2013) Neurodevelopmental fetal assessment using KANET scoring system in low and high risk pregnancies. J Matern Fetal Neonatal Med 26 363-368.

32. Abo-Yaqoub S, Kurjak A, Mohammed AB, Shadad A, Abdel-Maaboud M (2012) The role of 4-D ultrasonography in prenatal assessment of fetal neurobehaviour and prediction of neurological outcome. J Matern Fetal Neonatal Med 25: 231236.

33. Talic A, Kurjak A, Stanojevic M, Honemeyer U, Badreldeen A, et al. (2012) The assessment of fetal brain function in fetuses with ventrikulomegaly: the role of the KANET test. J Matern Fetal Neonatal Med 25: 1267-1272.

34. Kurjak A, Talic A, Honemeyer U, Stanojevic M, Zalud I (2013) Comparison between antenatal neurodevelopmental test and fetal Doppler in the assessment of fetal well being. J Perinat Med 41: 107-114. 